DOI: $10.5277 /$ epe 160114

\author{
MOHAMED ALWAELI ${ }^{1}$
}

\title{
END-OF-LIFE VEHICLES RECOVERY AND RECYCLING AND THE ROUTE TO COMPLY WITH EU DIRECTIVE TARGETS
}

\begin{abstract}
In an attempt to reduce waste originating from end-of-life vehicles (ELVs) which is becoming a serious environmental problem, the European Union enforced in 2000 the End-of-Life Vehicles Directive 2000/53/EC. Each European member state has to comply with the achievement of the following recycling and recovery targets: $80 \%$ and $85 \%$ by 2006 and increasing to $85 \%$ and $95 \%$, respectively, by 2015 . The required and achieved recovery and recycling targets for ELVs in Poland in 2011 have been discussed and compared. The data shows that the achieved targets of recovery and recycling were about $82 \%$ and $80 \%$, respectively. Therefore, the barrier factors affecting management of ELVs have been identified and the route useful to comply ELVs recovery and recycling in Poland and for other developing countries has been presented. The experience shows that this goal could be achieved by energy recovery and materials recycling of automotive shredder residue.
\end{abstract}

\section{INTRODUCTION}

End-of-life vehicles (ELVs) are one of the recently emerging waste streams in the world. It is a challenge to treat the increasing flow of these waste due to limited resources, environment protection as well as to enhance the image of automobile industries that implement environmentally sound management practices.

Recycling is essential method to solve this problem. It is the first waste management technique that should be applied [1] which can be followed by various treatment and storage techniques. Moreover, recycling is one of principal processes which prevent landfilling and other general environmental pollution, and increasing the efficiency of production. It is also necessary to manage the disposal of enormous quantities of hazardous waste.

${ }^{1}$ Silesian University of Technology, Faculty of Energy and Environmental Engineering, Department of Technologies and Installations for Waste Management, ul. Konarskiego 18, 44-100 Gliwice, Poland, e-mail: mohamed.alwaeli@polsl.pl 
Due to the coming into force of the 2000/53/EU Directive on ELVs, Poland, has to comply with the achievement of the following recycling and recovery targets: $80 \%$ and $85 \%$ rising, respectively, to $85 \%$ by 2006 and $95 \%$ by 2015 . In Poland, new laws and regulations have been established for the demands of the ELVs recycling network in Poland. Technical and organizational guidelines for dismantling stations and vehicle disposal units have been prepared. Moreover, methods of funding recycling and recovery network have been laid down.

The rapid growth of the number of vehicles in Poland and the existing age structure of the national vehicle fleet with a considerable share of vehicles aged 11-30 years, will inevitably lead to an increase in the scrapping of motor vehicles. The most appropriate solution to this problem is the development of recovery and recycling systems. The recovery and recycling of secondary materials from waste is becoming an increasingly important task for contemporary civilization. It is caused by rapid depletion of raw materials as well as by degrading character of waste disposal. Recycling not only reduces the amount of waste but also mitigates depletion of natural resources by economic development $[2,34]$.

Thus, recycling ELVs should be seen as an activity which contributes to environmentally safe dismantling, bringing them back to economic circulation and reusing parts and materials derived from them. The recycling process also involves discarded materials and parts arising from the routine operations of vehicles. Generally, major groups of materials and parts such as scrap metal (iron, aluminium, copper), operation fluids (oils, coolants, brake fluids), tyres and other rubber parts, batteries, plastic components, glass, textiles and other car parts and units for regeneration should be recovered and recycled.

This study analyzes the required and achieved levels of ELVs recovery and recycling in Poland. It identifies barrier factors affecting ELVs management. and presents the route which could be useful to comply ELVs recovery and recycling in Poland and in other developing countries.

\section{OVERVIEW OF THE ELVS RECOVERY AND RECYCLING IN POLAND}

\subsection{REVIEW OF THE POLISH LEGISLATIVE FRAMEWORK IN ELVS MANAGEMENT}

Aspiring to join the European Union, Poland was obliged to comply with the environmental protection requirements valid in the Community. In 2004, Poland became a full member of the EU. On its way to accession, Poland was obliged to comply with the environmental protection requirements applicable in the Community. Technical requirements for car design and minimum reuse and recovery rates for ELVs are the subject of a recent Polish directive on ELVs. In an attempt to reduce waste originating from ELVs, Poland enacted the End-of-Life Vehicles Directive Act in 2005. The aim of the 
act is to encourage manufacturers to develop components and vehicles that are easy to dismantle and recycle. Additionally, plans have been adopted according to the following principles:

- ELVs may be dismantled exclusively at dismantling stations and may be collected only by firms operating vehicle collection points or firms operating dismantling stations.

- Firms operating dismantling stations and those operating vehicle collection points are obliged to ensure that the treatment of ELVs is such that it does not damage the environment or public health,

- The operator of a dismantling station is obliged to accept all ELVs free of charge, except in certain situations (where a vehicle is incomplete or contains waste which does not come from that vehicle).

- Producers and importers of vehicles are obliged to ensure the existence of a vehicle collection network and thereby also the financing for the establishment of such a network.

- Car manufacturers are responsible for establishment of the ELVs collection network but they do not have to finance it.

\subsection{VEHICLE FLEET IN POLAND}

Due to widespread political and economic changes, the amount of vehicles in Poland increased from 9 million in 1990 to about 18 million in 2011 [5, 6]. A considerable proportion contains vehicles aged 10-15 years [5].

Since accession to the European Union, importation of used vehicles has remained consistent at a level of about 800-900 thousand annually [7]. The average age of imported vehicles is 10 years. Vehicles used for less than four years constituted $11.7 \%$, 4-10 years $-44 \%$, and vehicles older than 10 years - slightly above $44.3 \%$.

In Poland, the average age of a recycled vehicle is 17 years. Compared to other European Union countries, the life cycle of a car is much longer in Poland. The average vehicle exploitation time in Europe is 10-12 years [8].

\subsection{ELVS RECYCLING NETWORK IN POLAND}

Having acceded to the European Union, Poland was obliged to introduce a nationwide network of ELVs recycling. It consists of the producers and importers of vehicles and spare parts, state administrative bodies and units processing ELVs (recycling plants, dismantling stations, shredders, car collection points).

In Poland, the collection and dismantling of ELVs is carried out by approximately 950 small and medium-sized stations, which require a licence in order to carry out operations, as well as 138 collection points [9]. Apart from the dismantling stations, industrial shredding plants which grind the hulk of the vehicles constitute an important part of the recycling network. In Poland, only 10 shredders exist with capacity of $10^{6} \mathrm{t}$ per year. 


\subsection{THE LEVEL OF RECOVERY AND RECYCLING OF ELVS}

Until relatively recently in Poland, ELVs were abandoned by their owners with no legal consequences. The problem of ELVs recycling in Poland is relatively new. It was only legally regulated after the directives adjusting Poland to the regulations of the European Union had been introduced. The act of 20 January 2005 on the recycling of ELVs withdrawn from use brought into effect the requirements of the European Directive 2000. With the act of 20 January 2005 introducing the European Directive 2000/53/EC, collection points and dismantling stations have recently been created in Poland.

At the end of 2012, the EC published the results of the recovery and recycling rates for ELVs for 2011. In this year, about $284307 \mathrm{t}$ were generated in Poland. Out of all generated waste, about $82 \%$ were recovered, and around $80 \%$ was recycled [10].

ELVs recovery and recycling consists of: reuse, the recycling and recovery of materials from depollution and dismantling, materials from shredding, and materials arising in Poland and exported for further treatment.

Generally, out of all ELVs materials subjected to dismantling stations in 2011, about $109236 \mathrm{t}$ were recycled and about $115531 \mathrm{t}$ were recovered. In that year, nearly $759 \mathrm{t}$ were disposed of.

Materials from the shredding of ELVs arising in and treated in Poland are given in Table 1. The data shows that among materials from shredding, recycling of ferrous scrap remains at a high level. In 2011, $30917 \mathrm{t}$ of ferrous scrap was subjected to recycling. On the other hand, the level of recycling of non-ferrous materials was still very low. In this year, only about $1009 \mathrm{t}$ was recycled.

Table 1

Materials from shredding of ELVs arising in and treated in Poland in 2011 [11]

\begin{tabular}{|l|c|}
\hline \multicolumn{1}{|c|}{ Material } & $\begin{array}{c}\text { Recycling } \\
{[\mathrm{t}]}\end{array}$ \\
\hline Ferrous scrap & 30917 \\
\hline Non-ferrous materials & 1009 \\
\hline Automotive shredder residue & 6158 \\
\hline
\end{tabular}

In connection with the introducing of the common market within the European Union, area member states can export ELVs produced in their own territory to other Community states. The export of vehicles is effectuated for the purpose of further processing of raw materials. In the case of exported ELVs, the level of recovery and recycling is ascribed to the member state which organized the export. Among vehicles exported from Poland in 2011, total recovery and recycling of ELVs and their elements amounted to 3130 and $3130 \mathrm{t}$, respectively [11]. 


\subsection{RECYCLING OF END-OF-LIFE TYRES}

Poland was one of the first European countries to introduce a system of management for end-of-life tyres. This system was initiated by the biggest car tyre manufacturers and importers such as Goodyear, Michelin, Bridgestone, Continental and Pirelli. They entered into an agreement and established a joint-stock company under the name of Centrum Utylizacji Opon Organizacja Odzysku S.A. (Tyre Utilization Center Recycling Organization S.A., CUO). Its aim was to create a nationwide system of used tyre collection and transportation as well as to perform the recovery duties imposed by the act relating to entrepreneurs' duties in waste management on behalf of said entrepreneurs [12].

Within 7 years, the amount of recovered tyres has increased more than eightfold from just over $25000 \mathrm{t}$ in 2002 to about $213000 \mathrm{t}$ in 2011 [13]. The recovery of the vast majority of used tyres in Poland (over 70\%) is carried out through energy recovery. During this period, the level of used tyre recycling increased from $11.5 \%$ to about $96 \%$ [6]. Most of the tyres (up to 90\%) are recovered in cement kilns, used as alternative fuel for co-incineration.

This result was influenced by the fact that Poland has been a member of the European Union since 1 May 2004; hence, legislation has been enacted in Poland pertaining to waste packaging management as well as an obligation to meet the recycling levels dictated by European directives. An additional stimulus was brought about by a product charge for failing to comply with the recycling target levels. Tyres and vehicle manufactures and importers have been obliged to meet standards set by the Ministry of Environment relating to levels of end-of-life tyres recovery and recycling since 2004. The annual recycling levels of endof-life tyres are defined in Ordinance of the Council of Ministers of June 14th 2007 on the annual recycling levels of packaging and by-products waste. If the required levels within an accounting year are not met, entrepreneurs or end-of-life tire recycling operators have to pay the product fee.

The recycling level of end-of-life tyres constitutes a percentage value of the quotient of weight or quantity of recycled end-of-life tyres and weight or amount of tyres introduced into the market at a given time. In 2011, the required levels of recovering and recycling were 75 and $15 \%$, respectively. All waste management activities relating to tyres are concerned with the achievement of recovering and recycling levels dictated by the Council of Ministers of 30 June 2001, and influenced by the product charge. On the basis of statistical data produced by the Central Statistical Office of Poland, the required levels of recycling of end-oflife-tyres defined in the mentioned Ordinance were fulfilled. The achieved targets were 95.7 and $30.5 \%$, respectively [6].

\section{THE ROUTE TO COMPLIANCE ELVS RECOVERY AND RECYCLING}

Waste management should always deal with the use of waste as substitutes for primary materials. Waste should also be utilized as a source of energy. Reuse of waste 
should be treated as a way of reducing environmental pollution [14]. ELVs Directive is pushing for $85 \%$ and $80 \%$ by 2006 rising, respectively, to $95 \%$ and $85 \%$ by 2015 of the content of ELVs to be recovered and recycled. The Directive recycling/recovery targets are not to be met if only the metals present in the ELVs are separated and sent for recycling. As a consequence, recovery and recycling of ASR is the only way to achieve the EU targets. Auto shredder residue (ASR) is $25 \%$ of vehicle materials remaining after a vehicle has been shredded and removed of reusable parts and metals [15]. The ASR organic matter usually composes $40-65 \%$ of ASR total weight with a high calorific value [16]. Some of this energy can be recovered by modern technology solution, with subsequent reduction in the volume of material to be landfilled [17]. The non-combustible inert fraction can be collected from the treatment process and applied to other fields of industry [18].

It is necessary to establish a policy for an optimal management system of ASR. Two main strategies can be forecasted as alternative/complementary ways of reaching the recovery and recycling rates targeted by the EU directive: energy recovery and mechanical separation of materials and subsequent recycling.

\subsection{ENERGY RECOVERY}

According to the EU Directive 2000/53/EC, the fraction of ASR that is not recycled, but from which energy is recovered, by 2015 should not exceed $10 \%$ of the original ELVs's weight. Thus, the thermal treatment should be considered a complement to intensive dismantling and primary and/or secondary recovery activities, allowing a further increase of the recovery of ELVs. Moreover, thermal treatment of ASR considerably reduces volume and mass. Only the resulting inert ash must be landfilled [15]. Thermal treatment methods such as incineration, co-incineration with other waste, and pyrolysis have been investigated by several authors. Nadziakiewicz et al. [18] concluded that the ASR organic matter (i.e., plastics, rubber, and fibrous material) usually composes $40-65 \%$ of ASR total weight and have an interesting heating value $(15-30 \mathrm{MJ} / \mathrm{kg})$. Some of this energy can be recovered by incineration, with subsequent reduction in the volume of material to be landfilled.

Macro et al. [19] examined recycling of automobile shredder residues by means of pyrolysis. The pyrolysis experiments have been carried out in a non-stirred batch $3.5 \mathrm{dm}^{3}$ autoclave at 400,500 and $700{ }^{\circ} \mathrm{C}$ for $30 \mathrm{~min}$. The authors concluded that pyrolysis appears to be an appropriate technique for recycling heavy ASR, since valuable solids (38-39\%), liquids (20-29\%) and gases (31-41\%) are obtained, while this is not the case for the light ASR, which does not yield valuable products. Concerning temperature $500{ }^{\circ} \mathrm{C}$ is enough to produce total decomposition of the ASR organic matter. Increasing temperature over $500{ }^{\circ} \mathrm{C}$ increases gases to the detriment of liquids, but hardly varies the characteristics of the products. Sequential gasification and incineration tests were reported by [20]. It is concluded that the sequential gasification and combustion 
system reaches appealing energy and environmental performances, despite the unfavourable characteristics of ASR. Ippolitoa et al. [21] studied the recovery by thermal treatment of manganese and zinc from a mixture of zinc-carbon and alkaline spent batteries based on the different phase change temperatures of the two metal-bearing phases. In this research ASR, containing $68 \%$ of carbon, was added to the mixture to act as a reductant to metallic $\mathrm{Zn}$ of the zinc-bearing phases. The mixture was subsequently heated in various atmospheres ( $\mathrm{air}, \mathrm{CO}_{2}$ and $\mathrm{N}_{2}$ ) at 900,1000 and $1200{ }^{\circ} \mathrm{C}$ and stoichiometric excess of ASR $(300 \%, 600 \%$ and $900 \%)$. Characterization of the mixture and of the residues of thermal treatment was carried out by chemical analysis. The results show that recovery of $99 \%$ of zinc (grade $97 \%$ ) is achieved at $1000{ }^{\circ} \mathrm{C}$ under $\mathrm{N}_{2}$ with a stoichiometric excess of car-fluff of $900 \%$. This product could be suitable for production of new batteries after refining by hydrometallurgical way. Recovery of $\mathrm{Mn}$ around 98\% in the residue of the treatment is achieved at any temperature and atmosphere tested with a grade of $57 \%$ at $900 \%$ excess of car-fluff. This residue is enriched with manganese oxide and could be used in the production of iron-manganese alloys.

\subsection{MECHANICAL SEPARATION OF MATERIALS AND SUBSEQUENT RECYCLING}

ASR generated from vehicle shredding is difficult to sort. Developing the separation technologies and finding recycling possibilities for the products gained from the separation will greatly help to meet the 2015 recycling quotas. Separation of the ASR components is required to improve the energy value, as well as to reduce residual ash or remove problematic constituents. A further reduction in ASR to be disposed of therefore calls upon either incineration or the use of thermo-chemical processes such as pyrolysis or gasification. This will also allow to meet the European reuse and recovery targets of $95 \%$.

Heavy metals must be removed from ASR before energy recovery and recycled in order to meet the regulatory limits of the final application [15]. Certain heavy metals can easily be removed by mechanical separation. According to Osada et al. [22], low boiling point heavy metals such as $\mathrm{Pb}$ and $\mathrm{Zn}$ were distributed in the fly ash at the rates of $91 \%$ and $97 \%$, respectively. More than $94 \%$ of high-boiling-point heavy metals such as $\mathrm{Fe}$ and $\mathrm{Cu}$ were distributed in the metal fraction. About $95 \%$ of $\mathrm{Na}$ and $\mathrm{K}$ was also distributed in the fly ash. These results indicate that the recovery of heavy metals such as lead and zinc in the fly ash can constitute an ideal approach to resource recycling. Via the recycling of fly ash, all the products discharged during ASR treatment can be utilized effectively for the complete realization of an ASR recycling system that requires no final disposal sites.

The major plastics used in a vehicle are polypropylene, polyurethane, polyvinylchloride and acrylonitrile butadiene styrene, which represent together over $60 \%$ of the plastic fraction [23]. Plastic fractions can be collected from the treatment process and applied to other fields of industry. Scientist [24] performed and compared the chemical and physical properties of recycling of $100 \%$ post-consumer plastic with similar 
products manufactured from virgin resins. They claim that ASR plastics can be recycled via mechanical techniques if the polymer postconsumer polypropylene resins are separated from ASR. Their results prove that high-quality products can be manufactured from $100 \%$ postconsumer recycled plastic materials. The materials specifications of these recycled plastics are equivalent to or better than those listed for virgin polymer resins.

Fine sized ASR fraction ( $<20 \mathrm{~mm}$ ) is difficult to mechanically separate. Furthermore, this fraction generally exhibits the worst combustion characteristics. Many researchers studied the possibilities of directly incorporating this fraction into products such as composites in concrete mixes. It typically contains about $30 \%$ of organic matter, as well as inorganic substances such as quartz, calcite, magnetite, hematite, anhydrite [25]. Pera et al. [25] used organic matter, as well as inorganic compounds of ASR as components of building materials. These elements are powerful retarders of ordinary Portland cement. They have investigated two alternatives: (i) transformation into aggregates after a thermal treatment followed by a chemical treatment or (ii) direct mixture into concrete with the use of calcium sulfoaluminate cement. It was concluded that this second approach is especially interesting to engineers and scientists.

\section{ELVs RECOVERY AND RECYCLING PROBLEMS IN POLAND}

The following factors responsible for the poor performance of ELVs recovery and recycling in Poland and probably in many other similar developing countries were observed:

- Increasing number of vehicles: from 1999 to 2011 the number of vehicles increased systematically. Streams of vehicles increased by $100 \%$ in 2011 in comparison to 1999. The rapid growth of the number of vehicles in Poland and the existing age structure of the national vehicle fleet will inevitably lead to an increase in the scrapping of motor vehicles.

- Increasing number of used vehicles: since accession to the European Union importation of used vehicles has remained consistent at a level of 800-900 thousand annually. Vehicles used older than 10 years constituted above $44 \%$.

- Waste collection is not efficiently planned: In Poland only, 10 shredders exist, thus creating a considerable barrier to the development of car waste processing. It is estimated that there should be at least twice as many to meet the growing demand. It is worth being aware of the fact that in such countries as Germany or France there are about 50 similar installations. The majority of Polish stations and collection points have serious problems acquiring vehicles for recycling because they are trapped in the black market acting on an unauthorised basis and not complying with any environmental requirements. 
- Problems with ASR: currently, nearly $50 \%$ of auto shredder residue is disposed of by landfilling. By 2015, Poland has to comply with the achievement of following recovery and recycling targets: $95 \%$ and $85 \%$, respectively. Public awareness of ELVs waste management is low.

\section{DISCUSSION}

Currently, in Poland there are approximately 950 authorised small and mediumsized stations, as well as 138 collection points and 10 shredders, scattered homogenously across the country. The data presented here shows that in 2011 the required recycling targets were met while recovery targets were not met in Poland; however, the achieved levels of recovery amounting to about $80 \%$ can be considered a good result. Besides metals, batteries, and tyres, recycling of ASR is difficult and a great proportion is subsequently deposited. As the data shows, in 2011, out of $284307 \mathrm{t}$ of ELVs, about $30917 \mathrm{t}$ of ferrous scrap and $1009 \mathrm{t}$ of non-ferrous materials was recycled.

Regarding to end-of-life tyres, the required levels of recovery and recycling were met. More than $90 \%$ were incinerated with subsequent recovery of energy. Targets relating to the recovery and recycling of end-of-life batteries in 2011 were fulfilled or, in some cases, even exceeded. While the required targets of recovery and recycling in 2011 were $50 \%$ both, the levels achieved were $59.5 \%$ and $58.2 \%$, respectively. This result was influenced by a product charge for failing to comply with the recycling target levels.

The main financial motive enabling the maintenance of the level of profitability, which is rather low nowadays, is the revenues from selling whatever excess material is possible. In the first place, scrap metal is sold to smelter plants. The revenues from this kind of scrap metal can constitute 30-40\% of the revenues from all scrapped elements. The second source of revenues is selling used spare parts, batteries and overworked oils.

\section{RECOMMENDATIONS}

A number of recommendations are made here, aimed at the development of ELVs recovery and recycling, which could be useful in Poland and in other similar developing countries. Currently, in Poland nearly $50 \%$ of auto shredder residue is disposed of by landfilling. Due to the coming into force of the 2000/53/EU Directive on ELVs, Poland has to comply with the achievement of the following recovery and recycling targets: $85 \%$ and $80 \%$ by 2006 increasing to $95 \%$ and $85 \%$ by 2015 , respectively. Thus, increasing the recovery and recycling of ASR is the key issue to achieve the European targets.

ASR generated from vehicle shredding is difficult to sort. Developing the separation technologies and finding recycling possibilities for the products gained from the separation will allow to meet 2015 recycling quotas. Separation of the ASR components is 
required to improve the energy value, as well as to reduce residual ash or remove problematic constituents

ASR has a favourable calorific value. The $95 \%$ reuse and recovery target can be met by applying in addition thermal incineration techniques

Enhanced recycling and recovery of ELVs, possibly in combination with incorporation of ASR into products, will allow to meet the European $85 \%$ target for reuse and recycling from 2015. Moreover, the 95\% reuse and recovery target can be met by applying in addition thermal incineration techniques. Additionally, to meet $85 \%$ and $95 \%$ targets in 2015 it is essential to:

- Unify the requirements, conditions and standards with which stations should comply.

- Develop the network of collecting and processing ELVs.

- Increase the number of shredders.

- Increase the recovery and recycling of ASR.

- Develop the dismantling process to be carried out so as to obtain the purest raw materials possible, which will result in a good sales price.

- Prosecute actions such as dismantling vehicles outside legal dismantling stations and trading in parts from dismantled vehicles on the black market. A lot of car owners prefer to dismantle their car and sell its parts at the car markets or online auctions. Illegal dismantling of used vehicles, inefficiency of dismantling subsidy system and decreasing prices of raw materials directly influence the profitability of activities performed by dismantling and recycling stations.

- Create a system modelled in which, subsidies are paid for the last owner of the vehicle who delivers it to a legally operating dismantling station for recycling. A subsidy for the last owner of the vehicle may be an incentive.

In addition to technical and financial requirements, it is necessary to enhance public awareness and participation to promote these activities. Public awareness and attitudes toward waste can affect all waste management stages.

\section{CONCLUSIONS}

Waste from ELVs is one of the recently emerging waste streams and needs to achieve the maximum recovery and recycling levels with less waste discharge. Inappropriate disposal and dismantling of ELVs will result in environmental pollution. Hence, if the process of disposal and dismantling can be regulated to proceed in an environmentally friendly manner, it will not only avoid the negative impact on the environment, but also improve the effectiveness of recycled substances and reduce the usage of natural resources. ELVs parts, which include metallic and non-metallic substances, are increasingly gaining recycling value due to the recent global shortage of raw materials. 
The establishment of a proper recycling system for ELVs will not only reduce the impact on the environment, but it will also facilitate the effective reuse of recycled resources.

Complete elimination of the informal economy is not possible, but one has to consider several options, which would impede illegal dismantling and selling parts derived from it, for instance, the introduction of penalties for failing to register imported vehicles and failure to notify the purchase or sale of the vehicle.

\section{REFERENCES}

[1] Alwaeli M., An economic analysis of joined costs and beneficial effects of waste recycling, Environ. Prot. Eng., 2011, 37 (4), 91.

[2] BolaAne B., Constraints to promoting people centred approaches in recycling, Habit. Inter., 2006, 30 (4), 731.

[3] BOR Y.J., CHIEN Y., Hsu E., The market interactive recycling system for waste packaging containers in Taiwan, Environ. Sci. Poland, 2004, 7 (6), 509.

[4] Alwaeli M. Application of granulated lead-zinc slag in concrete as an opportunity to save natural resources, Rad. Phys. Chem., 2013, 83, 56.

[5] CSO, Environment Protection, Central Statistical Office, Warsaw 2005.

[6] CSO, Environment Protection, Central Statistical Office, Warsaw 2012.

[7] SAMAR. Automotive Market Research Institute, 2009.

[8] Merkisz-Guranowska A., End-of-life Vehicles recycling in Poland, Institute for Sustainable Technologies - National Research Institute, Poznań-Radom 2007.

[9] FORS, Vehicles recycling forum association, Warsaw, Poland. http://fors.pl/pliki/Stacje_punkty.pdf [Accessed Jan 22, 2013].

[10] Eurostat., European Commission, Environmental Data Centre on Waste, 2013.

[11] Eurostat., European Commission, End-of-life vehicles: Reuse, recycling and recovery, Totals, http://appsso.eurostat.ec.europa.eu/nui/show.do?query=BOOKMARK_DS-176053_QID_5C047C73 _UID_-3F171EB0\&layout=TIME,C,X,0;UNIT,L,X,1;GEO,L,Y,0;WST_OPER,L,Z,0;INDICATORS, C,Z,1;\&zSelection=DS-176053INDICATORS,OBS_FLAG;DS-176053WST_OPER,GEN;\&rankName1 =WST-OPER_1_2_-1_2\&rankName2=INDICATORS_1_2_-1_2\&rankName3=TIME_1_0_0_0\& rank Name4=UNIT_1_2_1_0\&rankName5=GEO_1_2_0_1\&sortR=CUSTOM_-1_FIRST\&sortC=ASC_1_FIRST $\& \mathrm{rStp}=\& \mathrm{cStp}=\& \mathrm{rDCh}=\& \mathrm{cDCh}=\& \mathrm{rDM}=$ true $\& \mathrm{cDM}=$ true $\&$ footnes $=$ false $\&$ empty $=$ false $\& \mathrm{w}$ ai $=$ false $\&$ time_mode $=$ ROLLING\&lang=EN\&cfo $=\% 23 \% 23 \% 23 \% 2 \mathrm{C} \% 23 \% 23 \% 23 . \% 23 \% 23 \% 23$ [Last update: 07-11-2013].

[12] Eurostat., European Commission, Environmental Data Centre on waste, 2013. http://appsso.eurostat.ec.europa.eu/nui/submitViewTableAction.do [Last update: 07-11-2013].

[13] SoBIECKi M., The development of end-of-life tyres management in Poland, Waste Environ., 2009, 57, 43.

[14] Alwaeli M., Economic calculus of the effectiveness of waste utilization processed as substitutes of primary materials, Environ. Prot. Eng., 2011, 37 (1), 51.

[15] Vermeulen I., Caneghem J., Block C., Baeyensc J., Vandecasteele C., Automotive shredder residue (ASR): Reviewing its production from end-of-life vehicles (ELVs) and its recycling, energy or chemicals valorization, J. Hazard. Mater., 2011, 190, 8.

[16] Mirabile D., Pistelli M.I., Marchesini M., FalCiani R., Chiappelli L., Thermal valorization of automobile shredder residue: Injection in blast furnace, Waste Manage., 2002, 22 (8), 841.

[17] Redin L., HJelt M., MARKLUND S., Co-combustion of shredder residues and municipal solid waste in a Swedish municipal solid waste incinerator, Waste Manage. Res., 2001, 19 (6), 518. 
[18] Nadziakiewicz J., Pikon K., Stelmach S., Removal of hydrocarbon pollutants from syngas by using plasma-catalytic reactor, Przem. Chem., 2012, 91 (6), 1270.

[19] De Marco I., Caballero B.M., Cabrero M.A., Laresgoiti M.F., Torres A., Chomón M.J., Recycling of automobile shredder residues by means of pyrolysis, J. Ann. Appl. Pyrol., 2007, 79 (1-2), 403.

[20] Cho S.J., Jung H.Y., Seo Y.C., KIM W.H., Studies on gasification and melting characteristics of automobile shredder residue, Environ. Eng. Sci., 2010, 27 (7), 577.

[21] Ippolitoa N.M., Belardib G., Medicia F., PigaA L., Utilization of automotive shredder residues in a thermal process for recovery of manganese and zinc from zinc-carbon and alkaline spent batteries, Waste Manage., DOI: 10.1016/j.wasman.2015.12.033 (in press).

[22] OSADA M., TANIGAKI T., TAKAHASHI S., SAKAI S., Brominated flame retardants and heavy metals in automobile shredder residue (ASR) and their behavior in the melting process, J. Mater. Cycles Waste. Manage., 2008, 10, 90.

[23] Joung H.T., Cho S.J., SeO Y.C., KIM W.H., Status of recycling end-of-life vehicles and efforts to reduce automobile shredder residues in Korea, J. Mater, Cycles Waste Manage., 2007 (2), 159.

[24] Ambrose C.A., Hooper R., PotTer A.K., Singh M.M., Diversion from landfill: quality products from valuable plastics, Res. Cons. Rec., 200236 (4), 309.

[25] Pera J., Ambroise J., ChabAnnet M., Valorization of automotive shredder residue in building materials, Cement Concrete Res., 200434 (4), 557. 